\title{
2. DEVELOPMENT OF A HIGH-RESOLUTION CALCIUM CARBONATE STRATIGRAPHY FROM LOGGING DATA ${ }^{1}$
}

\author{
Kathleen A. Dadey ${ }^{2}$ and Mitchell Lyle ${ }^{3}$
}

\begin{abstract}
We calculate equations relating three different log-derived calcium carbonate estimates to laboratory measurements. Results indicate good correlations between the log and laboratory data sets, supporting the use of log data to derive carbonate stratigraphies. The best log estimate of laboratory values was generated from normalized yields of calcium, a method that can be completed on board ship. This method has the added advantage of providing the opportunity to guide shipboard sampling of the cores.

Limitations of log methods result from potential depth mismatches, differences in the volumes measured, and the fact that logging tools and laboratory equipment are measuring different components of calcium carbonate (laboratory measurements are acid-soluble carbonate; log measurements are total calcium). Another limitation of using log data to estimate calcium carbonate is that log measurements alone cannot predict carbonate values directly. Some laboratory data are necessary to develop the regression equations that relate $\log$ data to $\mathrm{CaCO}_{3}$.
\end{abstract}

\section{INTRODUCTION}

Calcium carbonate $\left(\mathrm{CaCO}_{3}\right)$ stratigraphies in the equatorial Pacific have been demonstrated to provide invaluable information about paleoceanographic and paleoclimatic events on both long and short time scales. Variability in calcium carbonate content has been correlated with changes in productivity and bottom-water chemistry (e.g., Farrell and Prell, 1989; Lyle et al., 1988; Pedersen, 1983). However, development of accurate, long-term, high-resolution calcium carbonate stratigraphies has been hampered by poor core recovery and the time and monetary constraints associated with laboratory analyses.

Calcium carbonate stratigraphies developed from log data, on the other hand, present several obvious advantages. Logging is fast and, therefore, more efficient, relative to laboratory calcium carbonate analyses (even considering post-cruise processing of the log data). Even more importantly, log data are continuous, and represent data throughout the length of the borehole, including regions of poor core recovery and/or intervals in which core depth assignments are uncertain.

Although comparisons of in-situ values of various physical properties obtained by geophysical logging and laboratory measurements have been of interest throughout the life of the Ocean Drilling Program (e.g., Jarrard et al., 1989; Pratson et al., 1993; Urmos et al., 1993) and are becoming a major research focus, less research has been devoted to correlation of geochemical logging data and laboratory chemistry measurements. Correlation studies in the sediment column exist, but are few (Anderson et al., 1990; Broglia et al., 1990; Jarrard and Lyle, 1991). The reasons for the paucity of geochemical comparison studies is not necessarily a lack of interest, but may be related to the difficulty associated with extraction of elemental concentrations from the geochemical log data.

The goal of this research is to develop calcium carbonate stratigraphies from the geochemical (calcium) log. We use data available during the cruise (with minimal processing) and data from more sophisticated post-cruise processing. Geochemical log-derived calcium carbonate stratigraphies have a theoretical advantage over stratigraphies developed from log density measurements (see, for example, Mayer [1979] for a full discussion of the use of density measure-

1 Pisias, N.G., Mayer, L.A., Janecek, T.R., Palmer-Julson, A., and van Andel, T.H. (Eds.), 1995. Proc. ODP. Sci. Results, 138: College Station, TX (Ocean Drilling Program).

${ }^{2}$ Hawaii Institute of Geophysics, University of Hawaii, 2525 Correa Road, Honolulu. HI 96822, U.S.A.

${ }^{3}$ Center for the Geophysical Investigation of the Shallow Subsurface and Departmen of Geosciences, Boise State University, Boise, ID 83725, U.S.A. ments to estimate calcium carbonate), because the geochemical log response is generated directly by the calcium present in the formation. Here, we explore the possibility of obtaining calcium carbonate stratigraphy from the log data using several techniques, investigate their accuracy (using laboratory-derived values as the standard), and discuss the limitations of these methods.

\section{METHODOLOGY}

We investigated two possible methods for estimating calcium carbonate content from geochemical log data. The first method uses calcium estimates generated by post-cruise processing of the geochemical log data. The second calculates calcium carbonate values from normalized values of shipboard elemental yields. Virtually all calcium carbonate stratigraphies currently available have been developed from laboratory coulometry. Therefore, we use coulometerderived calcium carbonate as the standard against which we compare the log estimates.

We chose Hole $846 \mathrm{~B}$ for our comparison study. Site 846 , at approximately $3^{\circ} 5.7^{\prime} \mathrm{S}, 90^{\circ} 49.1^{\prime} \mathrm{W}$, is beneath a region of complex currents, where the South Equatorial Current interacts with upwelling waters from the Equatorial Undercurrent, on the southern edge of the Carnegie Ridge (Fig. 1). The overall recovery rate in Hole $846 \mathrm{~B}$ is $88 \%$, and in most cores above 350 mbsf, recovery approaches $100 \%$. Sediments are dominated by pelagic biogenic components, calcium carbonate (primarily nannofossils), and siliceous oozes. These deposits, which essentially constitute a two-phase system, are particularly well-suited for this study; they are characterized by a wide range of calcium carbonate contents, with only minor amounts of detrital terrigenous material. We chose seven cores (138-846B-27X through $-33 \mathrm{X}$ ) for a detailed comparison of $\log$ and laboratory data. Core recovery was excellent in this interval, ranging from $86.2 \%$ to $107 \%$ and averaging $99.2 \%$, with only one core (138-846B-27X) having less than $95 \%$ recovery. In addition, the chosen interval encompasses the entire range of calcium carbonate values encountered during Leg 138 and exhibits variability on scales from less than $1 \mathrm{~m}$ to tens of meters.

\section{Correlation of Laboratory Depth Scale}

Because coring and drilling may result in stretching and squeezing of the recovered sediment, core and log depths may not be identical, even if recovery approaches $100 \%$. Consequently, to ensure comparison of calcium carbonate estimates of the same depth intervals, we used CORPAC (Martinson et al., 1982) to adjust laboratory measure- 


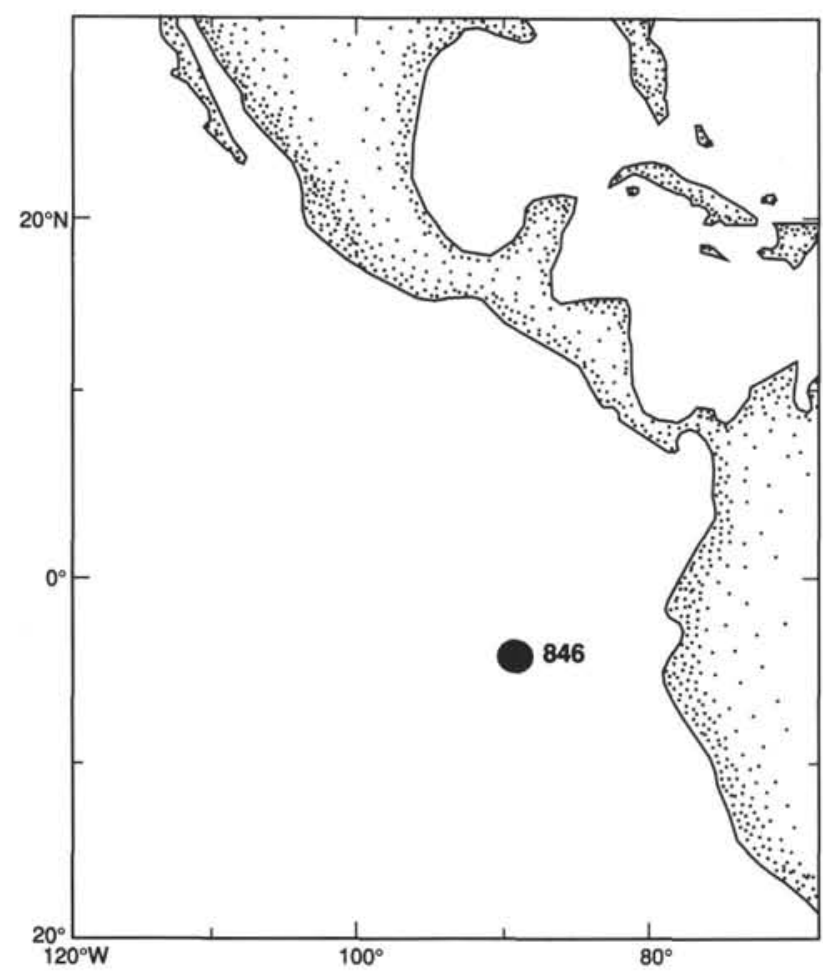

Figure 1. Base map showing the location of Hole 846B.

ment depths to the log scale. Laboratory GRAPE density values were compared with density values obtained by geophysical logging. Distinctive, prominent features in the laboratory data set were tied to similar features in the log density and the measurement depths were changed to correspond with the log depths. The GRAPE sample spacing is approximately $2 \mathrm{~cm}$; log data, which are reported each 15.24 $\mathrm{cm}$, represent averages over approximately $50 \mathrm{~cm}$ (see "Explanatory Notes" chapter in Mayer, Pisias, Janecek, et al., 1992). Therefore, fine-scale adjustments are possible.

Results of the correlation analysis for the entire 70 -m section are shown in Figure 2. Not only do the major peaks in the data sets match well, but small $(<5 \mathrm{~m})$ variations also correlate. A 20-m subsection of the longer data set (Fig. 3) confirms the validity of the correlation analysis. Several sections occur that do not correlate well, but in general, the match is excellent. We attribute most of the anomalously low GRAPE densities to high concentrations of siliceous microfossils (e.g., in the interval from approximately 290 to $305 \mathrm{mbsf}$ ). The GRAPE calibration standard is aluminum (e.g., Boyce, 1976), which has a density similar to that of calcium carbonate and aluminosilicates, but which is higher than biogenic silica. All laboratory measurements presented here are reported at the log-corrected depths.

\section{Laboratory Calcium Carbonate Measurements}

Laboratory calcium carbonate was measured on samples spaced at intervals of approximately 15 to $30 \mathrm{~cm}$ from 245.2 to $312.4 \mathrm{mbsf}$ (core depths; Cores 138-846B-27X to -33X) using a Coulometrics carbon dioxide coulometer. Both shipboard measurements and post-cruise analyses are included in the laboratory data set. Samples react with acid (perchloric, in this case) and carbon dioxide gas is evolved. The carbon dioxide is absorbed into a colorimetric solution that changes color as it reacts with the carbon dioxide. The solution is titrated back to its original color with a base, the volume of which is proportional to the concentration of carbon dioxide. The weight percent of the acid soluble carbonate can then be calculated from the carbon dioxide concentration and the sample weight (e.g., Huffman, 1977). The largest source of error in these measurements results from weighing the samples. We

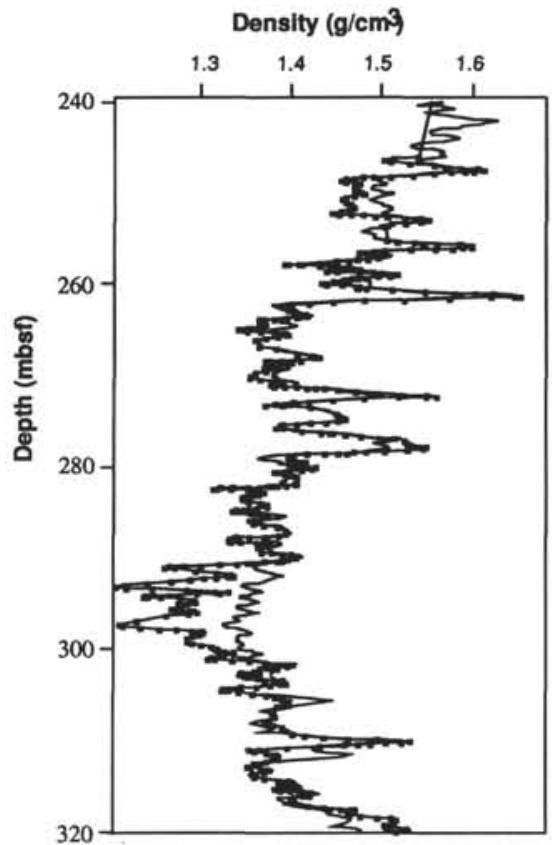

Figure 2. Log-derived and laboratory GRAPE density (correlated to log scale) vs. depth in the comparison interval, from 240 to 320 mbsf.

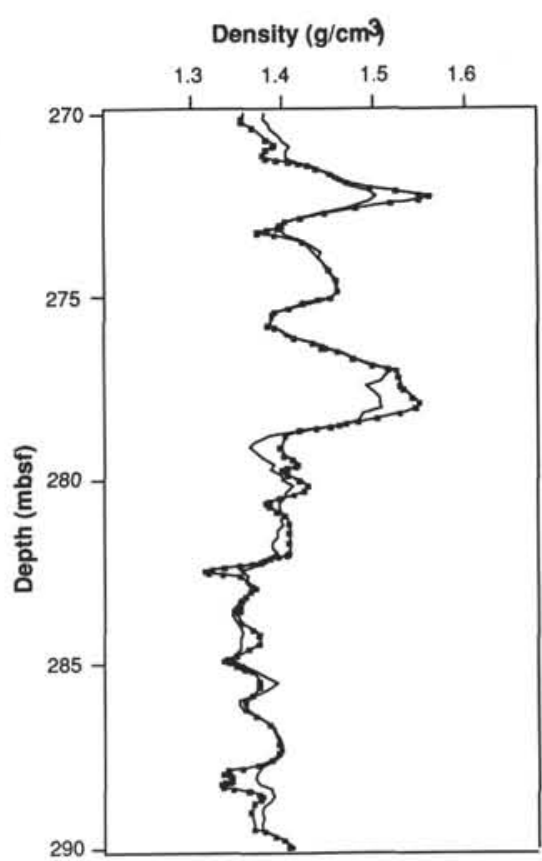

Figure 3. Log-derived density and laboratory GRAPE density (correlated to $\log$ scale) vs. depth in the interval from 270 to 290 mbsf.

used a Mettler balance accurate to $0.0001 \mathrm{~g}$. Post-cruise analyses included frequent calibration of the coulometer (approximately one calibration per 25 samples). All carbonate is assumed to be in the form of calcium carbonate. Precision of these measurements is $\pm 0.1 \%$ calcium carbonate.

\section{Geochemical Logs}

Raw geochemical log data consist of yields of natural gamma-ray emissions from thorium, uranium, and potassium, recorded by the 


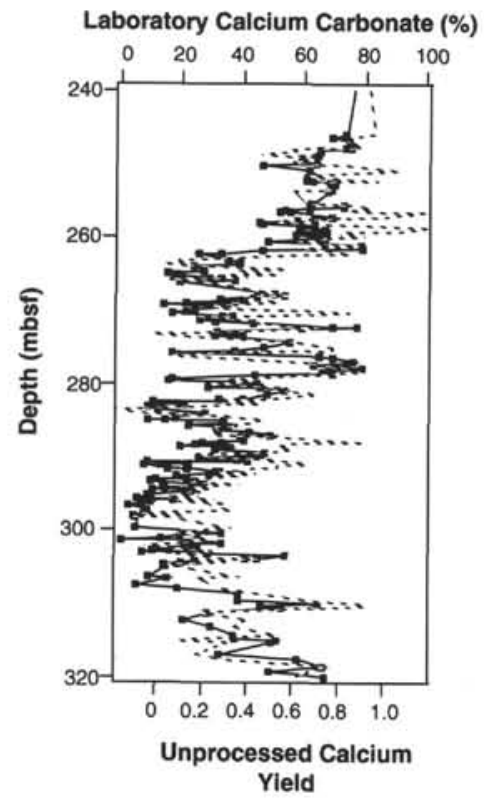

Figure 4. Raw (unprocessed) $\log$ yields of calcium and laboratory values of calcium carbonate vs. depth in the comparison interval. Dashed line = unprocessed log yields, and square data points (connected by solid line) $=$ laboratory data.

natural gamma-ray tool (NGT), and those induced by neutron activation of sediments, recorded by the geochemical spectroscopy tool (GST). Elements that are detected by the GST are silicon, iron, calcium, titanium, sulfur, gadolinium, hydrogen, and chlorine. Typically, yields are normalized, so that the total gamma-ray yield from these elements sums to one. In addition, aluminum can be detected by the aluminum clay tool (ACT). Recent improvements in logging equipment (e.g., inclusion of a boron sleeve that reduces the anomalous dominance of chlorine over other elements) and post-cruise processing have improved the accuracy and, therefore, the potential usefulness of geochemical log data.

We use the geochemical log data to calculate three estimates of calcium carbonate. The first is obtained from unprocessed data available on board the ship; these are "raw" calcium yields and are not expressed as concentrations; the second is generated by the standard geochemical post-cruise processing completed by the Borehole Research Group at Lamont-Doherty Earth Observatory. The latter is discussed in detail in Billeaud et al. (this volume). The Schlumberger geochemical logging tool string provides shipboard measurements of elemental yields of 12 elements. The only major rock-forming (i.e, solid phase) elements not detected are magnesium and sodium. Although an estimate of the sum of magnesium + sodium can be obtained during post-cruise processing (Hertzog, 1987), inclusion of this estimate generally reduces the accuracy of the log data (E. Pratson, pers. comm., 1993). Post-cruise processing includes corrections for hole size changes, natural activities, interference, and potassium contained in the drilling mud. Estimates of the oxide weight percents are summed to $100 \%$.

The third procedure estimates calcium as the relative percentage in the sum of raw (i.e., shipboard) elemental yields of calcium, silicon, iron, and sulfur. In other words, normalized calcium $=$ calcium yield/(calcium + silicon + iron + sulfur) yields.

The pelagic nature of Leg 138 deposits and small concentrations of terrigenous material led us to assume that all calcium detected by the logging tool exists as biogenic calcium carbonate. The validity of this method rests on the assumption that these four elements represent the only important rock-forming elements in the sediments investigated. Other major rock-forming elements, aluminum and potassium,

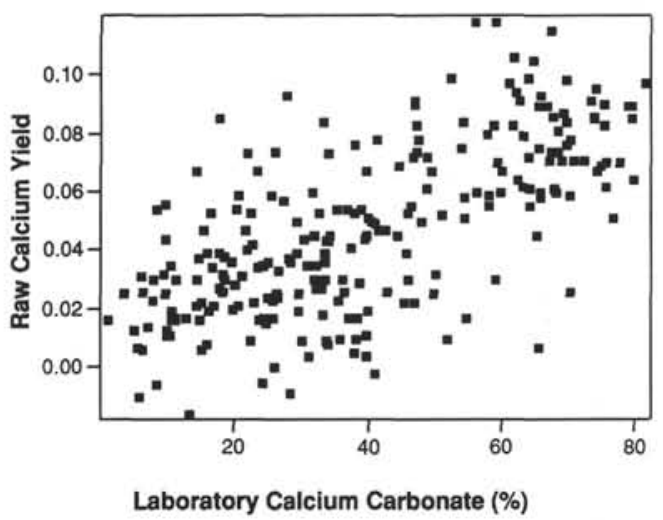

Figure 5. Raw (unprocessed) log yields of calcium vs. laboratory values of calcium carbonate in the comparison interval.

are found primarily in detrital clays that are present in small quantities in these sediments. Therefore, we are reasonably certain that our assumption is appropriate in these sediments.

This method can be used with either shipboard elemental yields or with post-cruise processed yields. We used the shipboard data in this investigation to examine the usefulness of this procedure on board the ship. This method has the added advantage that the results are not influenced by borehole or pore fluid concentrations.

\section{RESULTS}

Plots of unprocessed (i.e., "raw" shipboard) yields of calcium and laboratory calcium carbonate vs. depth are shown in Figure 4. A fivepoint smoothing filter was applied to the log data to reduce the "noisiness" inherent in the raw yields. Because yields are not percentages, a direct comparison between laboratory calcium carbonate and the raw yield values is not appropriate. Nevertheless, the depths of maxima and minima in the two data sets are generally coincident (Fig. 4), and the values correlate fairly well, with a regression coefficient $(r)$ of 0.67 (Fig. 5).

Estimates of calcium carbonate based on the standard post-cruise processing of the geochemical data and laboratory calcium carbonate vs. depth in the comparison interval are shown in Figure 6. Although the correlation between the two data sets is reasonably good in depth intervals where processed calcium carbonate values are greater than zero, these sections comprise only $36.3 \mathrm{~m}$, or about $45 \%$ of the comparison interval. A cross-plot of laboratory calcium carbonate vs. processed log values (shown in Fig. 7) clearly illustrates the dominance of the zero log values. In our calculation of the regression equation between these two data sets, we examined only the intervals of positive values. The resulting equation is

$$
\begin{gathered}
\text { Laboratory calcium carbonate }=43.45 \\
+(0.25 \cdot \text { processed log calcium carbonate })
\end{gathered}
$$

The regression coefficient $(r)$ is 0.53 .

The plot of the normalized calcium yield values (expressed as percentages) and laboratory calcium carbonate vs. depth is presented in Figure 8. A reasonably good correlation exists between the log estimates and laboratory values (Fig. 9). The regression equation is

\section{Laboratory calcium carbonate $=0.052$}

$+(0.9 \cdot$ normalized calcium yield $)$.

The regression coefficient $(r)$ is 0.76 . 


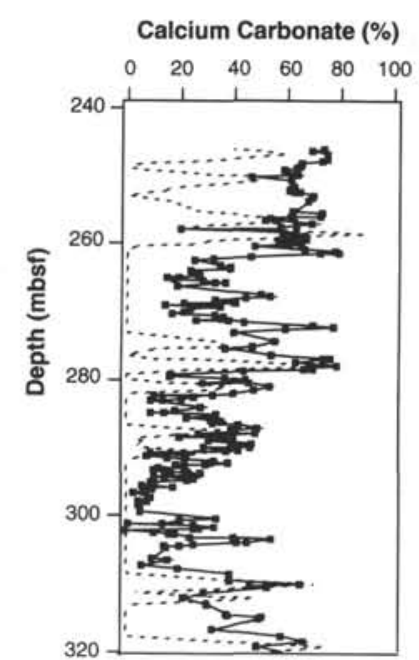

Figure 6. Log estimates (post-cruise processing) of calcium carbonate and laboratory values of calcium carbonate vs. depth in the comparison interval. Dashed line $=\log$ estimate, and square data points (connected by solid line) $=$ laboratory data.

\section{DISCUSSION}

Based on the regression equations, the normalized yield estimates are the best predictors of laboratory calcium carbonate values of the methods investigated. The relationship between the normalized yields and the laboratory data is the closest to a one-to-one relationship, both in terms of the slope and the intercept of the correlation equation. We also examined the applicability of the log estimates by calculating the differences (referred to as residuals) between laboratory calcium carbonate and the log estimates at coincident depths, where

Residual $=$ laboratory calcium carbonate $-\log$ estimate.

The results of these comparisons are as follows:

\begin{tabular}{|c|c|c|c|}
\hline Residual & $\begin{array}{l}\text { Mean } \\
(w t \%)\end{array}$ & $\begin{array}{c}\text { Standard } \\
\text { deviation } \\
(w t \%)\end{array}$ & $N$ \\
\hline Unprocessed yield & 0.004 & \pm 15.8 & 237 \\
\hline Processed $\mathrm{CaCO}_{3}{ }^{\mathrm{a}}$ & 5.060 & \pm 17.9 & 60 \\
\hline Normalized yield & 0.370 & \pm 13.8 & 194 \\
\hline
\end{tabular}

The nonzero mean associated with the processed calcium carbonate indicates that the log estimate consistently underestimates $\mathrm{CaCO}_{3}$ relative to the laboratory values. This is probably an artifact of the choice of log data set, however. As can be seen in Figure 6, the decreases to zero calcium carbonate and the subsequent rebounds in the log data set are gradual. Judgments were made regarding which $\log$ values to include in the analysis; apparently, we included some values that are too low. The unprocessed yield data and the normalized yields, on the other hand, generate calcium carbonate estimates that are not skewed and have lower standard deviations. Thus, they are better predictors of calcium carbonate. Although the interval between approximately 290 and $300 \mathrm{mbsf}$ appears to be characterized by a more restricted range of residual values and a slightly smaller average value, no obvious relationships between the residuals and depth were observed (see, e.g., Fig. 10).

We examined the sensitivity of the regression equations to laboratory sample density and the length of the comparison interval. Our preliminary results suggest that all equations are sensitive to these factors. A comparison interval that is $20 \mathrm{~m}$ shorter, for example, results in a degradation of the one-to-one relationship developed from

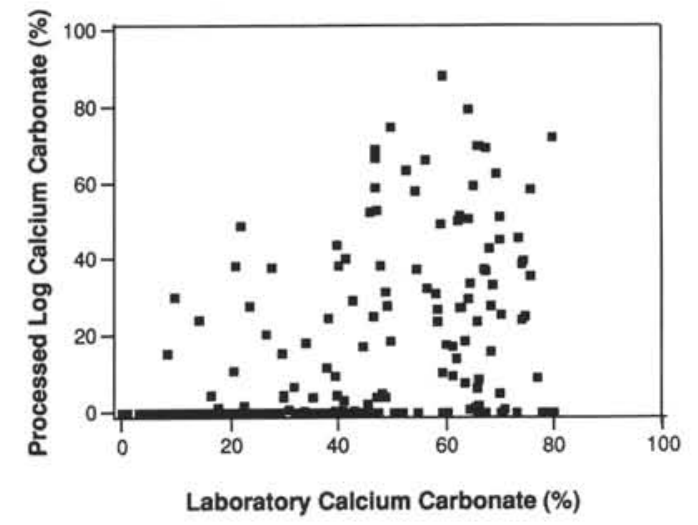

Figure 7. Log estimates (post-cruise processing) of calcium carbonate vs. laboratory values of calcium carbonate throughout the comparison depth.

the complete data set. The regression equation relating laboratory and normalized yield estimates in the interval from 250 to $310 \mathrm{mbsf}$ is

Laboratory calcium carbonate $=5.29+(86.3$. normalized calcium $)$.

Similarly, a larger laboratory sampling interval of $50 \mathrm{~cm}$ produces significant changes in the regression equations. Although examination of larger sampling intervals over greater depth intervals is beyond the scope of this research, our preliminary investigation suggests that this type of data could yield good results.

\section{LIMITATIONS AND SOURCES OF ERROR}

A primary limitation associated with using logging geochemical data to estimate calcium carbonate is that the methods that produce the best fit to the laboratory data (i.e., unprocessed and normalized yields) require laboratory analyses to develop the correlation equations. Because the number and density of the samples required for a good correlation analysis are likely to be dependent on sediment composition and other characteristics unique to each example, determination of general values of sampling density are beyond the scope of this research.

The most likely source of error when comparing any logging and laboratory data is depth mismatches. Another source of discrepancies between log-derived and laboratory calcium carbonate values is measurement of different volumes. Laboratory measurements usually are performed using samples of approximately $5 \mathrm{~cm}^{3}$ (the actual volume measured is much less, but the $5-\mathrm{cm}^{3}$ sample is assumed to be homogeneous). The logging tool, on the other hand, averages over a vertical length of about $0.5 \mathrm{~m}$ and a total volume of nearly $1 \mathrm{~m}^{3}$ (Jarrard and Lyle, 1991). Because the scale of the variability in the comparison interval is on the order of $10 \mathrm{~cm}$ or less, the log samples are not directly comparable to those analyzed in the laboratory.

The other potential source of differences in laboratory and logging estimates of calcium carbonate is that the two methods actually measure different components of the mineral; the laboratory coulometer measures acid-soluble carbonate; the logging tool, on the other hand, measures calcium. Consequently, comparisons of the two values are only appropriate in sediments in which these two assumptions are valid. In the case of laboratory carbonate estimates, the assumption holds in most deep-sea sediments. With logging data, the methods we present here are most accurately applied to pelagic deposits similar to those studied. For example, our methods would overestimate calcium carbonate in sediments that contain high percentages of feldspars or other minerals containing large amounts of calcium. Nevertheless, the methods can be used in more complex regions that have significant detrital calcium. Normative corrections of the calcium yield based on the aluminum content (measured by a different logging tool) can be applied to correct for the detrital calcium content. Such corrections 


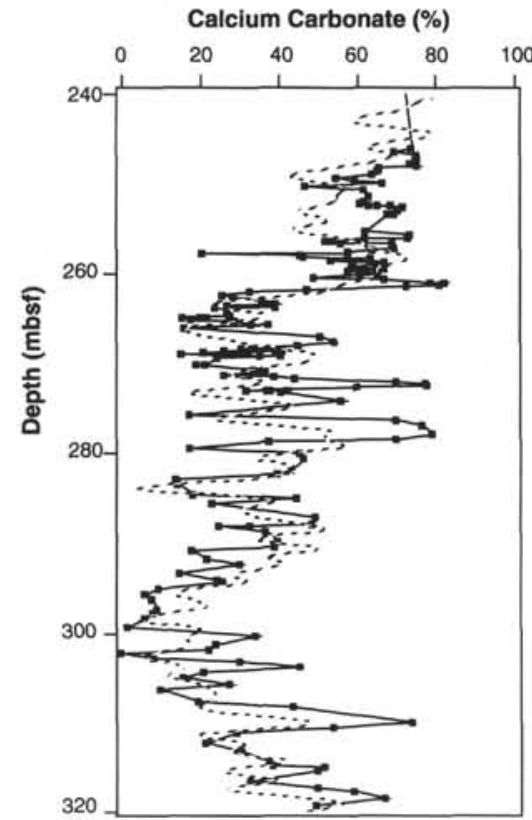

Figure 8. Log estimates (normalized yield estimates) and laboratory values of calcium carbonate vs. depth in the comparison interval. Dashed line $=$ normalized log estimates, and square data points (connected by solid line) $=$ laboratory data.

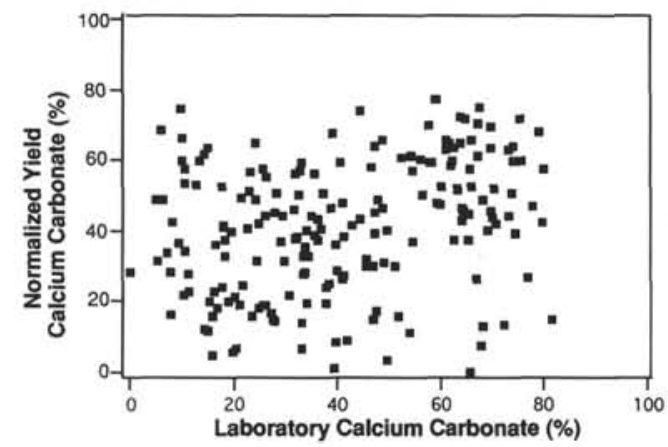

Figure 9. Log estimates (normalized calcium yields) vs. laboratory values of calcium carbonate throughout the comparison interval.

would require calibration at many locations, however, and would cause the error in log-estimated calcium carbonate to be greater

At least at present, another limitation is that the accuracy of any log estimate of calcium carbonate will be severely degraded in the shallow portion of the deposit, where the pipe ("casing") has been left in the hole during logging. This is because the signal derived from cased sediments is dominated by the signal from the pipe and is overwhelmed by that of iron in the metal casing. Although useful geochemical information can be extracted from data obtained from these depths, currently we do not recommend using the techniques presented here for estimating calcium carbonate in cased sections. The cores in this interval (i.e., the top 70-100 mbsf), however, are generally the most densely sampled on board the ship.

Other limitations are imposed by the post-cruise processing of the geochemical logging data. As can be seen in Figure 6, negative calcium carbonate measurements (expressed as zero values) are common. These negative values result from the highly porous nature of the Hole $846 \mathrm{~B}$ sediments. Because the bulk of the signal results from pore water and only a small percentage is derived from the sediment, the statistics associated with the geochemical oxide calculation are poor.

The normalized yield method is most useful in sediments similar to those examined here (i.e., essentially binary biogenic systems contain-

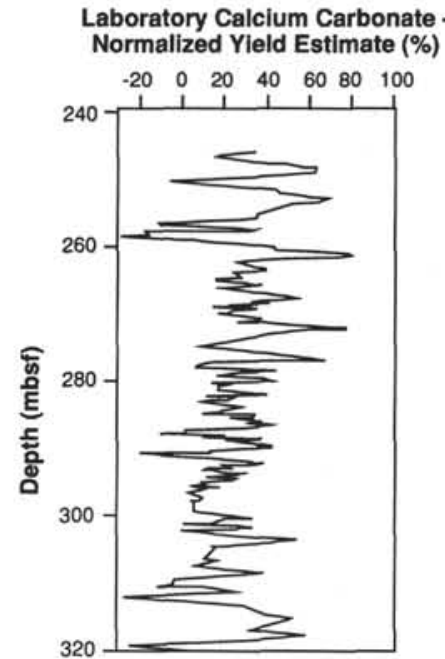

Figure 10. Normalized log calcium yield residual values vs. depth in the comparison interval.

ing low concentrations of clay minerals). If the sediments contain large amounts of detrital clay, the method will still work, provided that the chemical composition of the clay minerals remains constant and, thus, the proportions of unmeasured elements remain constant relative to those measured. In sediments that contain widely varying clay mineral types, the normalized yield method has a good likelihood of failure. In fact, even these Hole $846 \mathrm{~B}$ sediments, which have minimal detrital material, display indications that the concentrations of other elements cannot be dismissed completely. This conclusion is based on the fact that the slope of the equation relating laboratory and normalized yieldderived calcium carbonate values is not unity. Variations in the constituents of the sediment not accounted for in the normalization method are assumed to be the cause of the nonunity slope.

\section{SUMMARY}

Our results indicate that log-derived estimates of calcium carbonate are viable, simple, and quick. An added advantage is that estimates of calcium carbonate can be made on board the ship, essentially in real time, providing one with the opportunity for guiding shipboard sampling of the cores.

Further, our research indicates that, under the appropriate circumstances, log methods can be used to address paleoceanographic questions (i.e., that log calcium carbonate values can be used to develop an accurate stratigraphy for paleoceanographic purposes). The limitations of the $\log$ methods are that their applicability generally is limited to biogenic sediments and that none can be used to predict calcium carbonate directly.

\section{ACKNOWLEDGMENTS}

The authors wish to thank Borehole Research Group log analysts Beth Pratson and Lana Billeaud for their assistance with the postcruise processing. This research was funded in part by a USSAC/JOI grant to KAD and Roy Wilkens and NSF Grant No. OCE 9216983 to Roy Wilkens.

\section{REFERENCES ${ }^{*}$}

Anderson, R.N., Dove, R.E., and Pratson, E., 1990. Geochemical well logs: calibration and lithostratigraphy in basaltic, granitic and metamorphic rocks.

\footnotetext{
Abbreviations for names of organizations and publication titles in ODP reference lists follow the style given in Chemical Abstracts Service Source Index (published by American Chemical Society).
} 
In Hurst, A., Lovell, M.A., and Morton, A.C. (Eds.), Geological Applications of Wireline Logs. Geol. Soc. Spec. Publ. London, 48:177-194.

Boyce, R.E., 1976. Definitions and laboratory techniques of compressional sound velocity parameters and wet-water content, wet-bulk density, and porosity parameters by gravimetric and gamma ray attenuation techniques. In Schlanger, S.O., Jackson, E.D., et al., Init. Repts. DSDP, 33: Washington (U.S. Govt. Printing Office), 931-958.

Brewer, T.S., Lovell, M., Harvey, P., Pelling, R., Atkin, B., and Adamson, A., 1990. Preliminary geochemical results from DSDP/ODP Hole 504B: a comparison of core and log data. In Hurst, A., Lovell, M.A., and Morton, A.C. (Eds.), Geological Applications of Wireline Logs. Geol. Soc. Spec. Publ. London, 48:195-202.

Broglia, C., Schreiber, B.C., Cita, M.B., Chamley, H., and Dove, R., 1990. Mineralogical study of upper Miocene sediments from wireline logs and core measurements, Site 652, Ocean Drilling Program Leg 107 (Tyrrhenian Sea). In Kastens, K.A., Mascle, J., et al., Proc. ODP, Sci. Results, 107: College Station, TX (Ocean Drilling Program), 229-243.

Farrell, J.W., and Prell, W.L., 1989. Climatic change and $\mathrm{CaCO}_{3}$ preservation: an 800,000 year bathymetric reconstruction from the central equatorial Pacific Ocean. Paleoceanography, 4:447-466.

Hertzog, R.C., Colson, J.L., Seeman, B., O'Brien, M.S., Scott, H.D., McKeon, D.C., Wraight, P.D., Grau, J.A., Ellis, D.V., Schweitzer, J.S., and Herron, M.M., 1987. Geochemical logging with spectrometry tools. Soc. Pet. Eng. Pap., 16792.

Huffman, E.W.D., 1977. Performance of a new automatic carbon dioxide coulometer. Microchem. J., 22:567-573.

Jarrard, R.D., Dadey, K.A., and Busch, W.H., 1989. Velocity and density of sediments of Eirik Ridge, Labrador Sea: control by porosity and mineralogy. In Srivastava, S.P., Arthur, M.A., Clement, B., et al., Proc. ODP, Sci. Results, 105: College Station, TX (Ocean Drilling Program), 811-835.

Jarrard, R.D., and Lyle, M., 1991. High-resolution geochemical variations at Sites 723,728 , and 731 : a comparison of $x$-ray fluorescence and geochemi- cal logs. In Prell, W.L., Niitsuma, N., et al., Proc. ODP, Sci. Results, 117: College Station, TX (Ocean Drilling Program), 473-498.

Lyle, M., Murray, D.W., Finney, B.P., Dymond, J., Robbins, J.M., and Brooksforce, K., 1988. The record of Late Pleistocene biogenic sedimentation in the eastern tropical Pacific Ocean. Paleoceanography, 3:39-59.

Martinson, D.G., Menke, W., and Stoffa, P.L., 1982. An inverse approach to signal correlation. J. Geophys. Res., 87:4807-4818.

Mayer, L., 1979. Deep sea carbonates: acoustic, physical, and stratigraphic properties. J. Sediment. Petrol., 49:819-836.

Mayer, L., Pisias, N., Janecek, T., et al., 1992. Proc. ODP, Init. Repts., 138 (Pts. 1 and 2): College Station, TX (Ocean Drilling Program).

Pederson, T.F., 1983. Increased productivity in the eastern equatorial Pacific during the last glacial maximum (19,000 to $14,000 \mathrm{yr}$ B.P.). Geology, 11:16-19.

Pratson, E.L., Reynolds, R., Lovell, M.A., Pezard, P.A., and Broglia, C., 1992. Geochemical well logs in the Izu-Bonin arc-trench system, Sites 791, 792, and 793. In Taylor, B., Fujioka, K., et al., Proc. ODP, Sci. Results, 126: College Station, TX (Ocean Drilling Program), 653-676.

Urmos, J., Wilkens, R.H., Bassinot, F., Lyle, M., Marsters, J.C., Mayer, L.A., and Mosher, D.C., 1993. Laboratory and well-log velocity and density measurements from the Ontong Java Plateau: new in-situ corrections to laboratory data for pelagic carbonates. In Berger, W.H., Kroenke, L.W., Mayer, L.A., et al., Proc. ODP, Sci. Results, 130: College Station, TX (Ocean Drilling Program), 607-622.

Date of initial receipt: 30 April 1993

Date of acceptance: 27 April 1994

Ms 138SR-102 